\title{
Espectros de la nación: figuras desplazadas entre 'saudades' $y$ soledades ${ }^{* 1}$ Francisco Foot Hardman
}

En un discurso-memorial hecho en Octobre 1971, en São Paulo, el escritor José Geraldo Vieira, al final de su vida, cuando les agradecía a sus pares por el homenaje que le hacían pasados cuarenta años de su ficción, afirmaba:

\footnotetext{
[...] la memoria es un asilo con dos alas. En un de ellas, las saudades, esas ancianas paraliticas; en la otra, los complejos, eses locos domados con camisas de fuerza. Permitánme, ya ahora, confesarles que he extraído mis personajes de las dos alas. ${ }^{2}$
}

Interesantes tales palabras de ese médico, traductor infatigable, crítico de arte muy raro y novelista expulsado de la historia literaria fija en el canon nacionalista. Sus mayores creaciones ficcionales padecen exactamente de la falta de figuras bien ubicadas espacio-temporalmente, siendo más bien frecuentes los personajes-en-tránsito, desplazados en amplios escenarios preferiblemente cosmopolitas y panorámicos de la historia contemporánea - ningún autor brasileño a mi juicio hizo cuadro más vivo y dramático de las dos guerras mundiales que Vieira en novelas como A Quadragésima Porta (1943) y O Terreno Baldio (1961). Así que en el caso de la ficción de José Geraldo, el trabajo de la memoria posee ya la visión de las ruínas e incorpora un lirismo de fondo melancólico hecho de las pérdidas personales y coletivas como raíces de la poiesis y de lo ficticio, sin recaer ni en narrativas luctuosas ni en una prosa saudosista. Veánse, como ejemplos, la tuberculósis y el vicio del jugador en ese Mário dostoievskyiano de A Mulher que Fugiu de Sodoma (1931); el poeta loco 
Cássio Murtinho, personaje que tuvo existencia real y totalmente outsider a la manera de Lima Barreto en la belle-époque carioca, figura conmovedora en $O$ Território Humano (1936); el angel-fantasma doble del compositor musical y piloto aéreo Albano en A Quadragésima Porta; o las bellas y trágicamente evanescentes Adriana y Renata, desdoblamientos de un único amor vivido y perdido en la vida real, materias de evocación elegíaca en O Territorio Humano y en un viaje de ferrocarril en A Ladeira da Memoria (1950).

Nuestra hipótesis, aquí apenas esbozada en la referencia inicial a la literatura de José Geraldo Vieira - su obra misma como impresionante testimonio de un reconocimiento público y consagración crítica significativos en el período que va de 1930 a 1970, para despues caer en un olvido casi completo - es la de que hay un cierto linaje, más allá de escuelas o movimientos, que se remonta a mediados del siglo XIX hasta la modernidad literaria del siglo XX, que es el linaje de los desplazamientos geográficos e históricos, el cual ha ofrecido algunas de las representaciones poéticas más agónicas en el Brasil sobre la imposibilidad de una fundación nacional simétrica o armoniosa, ya que todas las construcciones identitarias así intentadas fueron productos ideológicos de la cultura dominante del "órden y progreso", siempre como marcha triunfal de la desmemoria capaz de apagar a los vestigios y señales del otro binomio, el de "muerte y progreso". Algunas de esas mejores figuraciones quedan así desechadas del canon nativista o nacionalista que ha presidido la formulación de líneas evolutivas compuestas o bien de regionalismos saudosistas fijados en paisajes transbordantes de sentimentalismos, o bien de naturalismos pintorescos prisioneros de clichés descriptivos tan delirantes cuanto reproducibles, donde las acciones humanas están ya por así decir encuadradas en una pre-consciencia edificante y autoreveladora.

En cambio, las figuraciones que aquí se comentan no se agarran al culto pasatista de saudades como palabra o concepto intraducible, mito quizá generalizado en las culturas lusófonas desde 1870 por la generación que mejor cantó y contó la decadencia portuguesa. Esa saudade en des- 
plazamiento puede buscar desde siempre a sus mejores traducciones o traductores en francas y libres lenguas, en tantos otros términos o expresiones del dolor inmensa de uno que sabe ya no poder volver a una patria desde hace mucho en destrozos; ni tampoco a la tierra materna desposeída ya de casa, de calor y de voz. Su corazón se perdió en el rumorear del mundo, cargando aquel desconcierto trágico del laberinto de las soledades no mejicanas sino más bien universales que Paz a todos nosotros legó y que Rulfo haya eternizado por los caminos fantasmales de Comala. Los páramos y los Páramos de Comala son paisajes, nombres y sombras de las soledades, acá mismo simultaneamente tomadas como sentimiento melancólico y lugar remoto, destierro y sueño con muertos, cementerio vivo y ciudad fugaz, punto extremo en el mapa y vidas arruinadas al borde de la gran pirámide narrativa llamada nación.

Pero las figuraciones de que hablamos tampoco no se dejan capturar por los extremos de la soledad, lo que aquí equivaldría a calarse en el agua silente y mortal del remordimiento. Están más bien en los intervalos y límites de la voz, entre la nostalgia (impracticable) de saudades y el exilio (insoluble) de soledades. Desplazadas, podrían seguir diciéndonos algo, aunque sus destinos estuvieran ya sellados. Pues es justo en esa su descreencia en el proceso civilizatorio y en la historia de la identidad nacional que se descubrirán sentidos e imágenes dignos de cualquiera estética y/o ética. Pero, perdón, ya casi me olvidava: debo hablar de Brasil, o por lo menos del sentimiento de no estar de todo ahí. ${ }^{3}$ Vamos a ver lo que pasó con algunas figuras, con algunas fantasías brasileñas, donde ya no se separan alegría y tristeza, donde las fronteras territoriales y temporales ya se han borrado para siempre.

Esa búsqueda, se podría ensayar en algunos de los prosistas y/o poetas más importantes de la literatura brasileña, intentando hallar en sus textos trazos característicos del proceso de desplazamiento sobre el cual venimos insistiendo. ?Sino, como negarle al ingenio de Machado de Assis, para empezar, esa formidable y melancólica invención narrativa, irónica, autoindicativa de su entera ficcionalidad, absurda como verdad fac- 
tual, todavía completamente entrañada en la verosimilitud de la artesanía literaria moderna, aspectos pertinentes en su novela Memórias Póstumas de Brás Cubas (1881)? Porque aquí lo que pasa es la distante mirada de un narrador muerto, las memorias escritas por una voz de ultratumba. Su libertad de vuelo, sin censura ni polémica de los mortales, es la de un cadáver. Su memoria es necesariamente impropia en su propiedad evocadora, crítica y melancólica, en su deseo expreso, firmado en las líneas finales de la novela, de no dejar a ningún heredero vivo el legado mayor de "nuestra miseria" (?cual "nuestra"? - ?humana, brasileña, pequeño burguesa carioca? - quizá todas las tres dimensiones...). La amargura de Brás Cubas no tiene lugar de reposo ni postumamente. Estaría presente, aún en Machado, en las sombrías evocaciones de otro narradormemorialista, el viejo que se despide de la vida en Memorial de Aires (1908), novela autobiográfica que sale en el mismo año de la muerte del autor.

De forma ciertamente más brutal y violenta, en Lima Barreto se puede perseguir los mismos hilos de narradores desplazados, como por ejemplo en el caso de Triste Fim de Policarpo Quaresma (1911; 1915), donde el protagonista transita entre un nacionalismo naïf, una cultura libresca sin lugar en la República "modernizadora” y la locura solitaria de un alma generosa y vulnerable ante el poder burocrático y militar de la máquina estatal; es el caso de ese otro narrador-memorialista de un suburbio triste de Rio, él mismo también déplacé ante el progreso de la metrópolis en Vida e Morte de M. J. Gonzaga de Sá (1919); es, finalmente, el caso de los trágicos y sublimes textos autobiográficos de Lima Barreto - sobre su propria experiencia como marginal del sistema político y literario, así como interno en un manicomio dos veces en la década del 1910, verdaderos y casi impenetrables "laberintos de la soledad" - y que solo serían editados postumamente en los anõs 1950 (Diario Íntimo; O Cemitério dos Vivos). ${ }^{4}$

Ya en los años 1920, en los dos exponentes del modernismo paulista, Mário de Andrade y Oswald de Andrade (que apesar del nombre no 
tenian ningún parentesco, ni sanguíneo ni temperamental) volvemos a encontrar huellas del nuestro tema. En Oswald, escritor de matices estéticos muy variados e irregulares en los resultados poéticos, dramáticos y narrativos, ha quedado bien conocida esa dificuldad que tuvo para fijar personajes con mayor densidad de caracteres sociales y sicológicos. Trabajando más en la vertiente satírico-paródica, sus dos narrativas más experimentales, Memórias Sentimentais de João Miramar (1924) y Serafim Ponte Grande (1933), esa última consagrada por Haroldo de Campos como "un gran no-libro", presentan narradores fugaces, siguiendo movimientos fragmentarios entre varios escenarios, casi caricaturas de sensaciones y personas pasajeras, o casi crónicas de escenas momentáneas como fotografías o postales. De otra parte, en su prosa más decadentista y dannunziana A Trilogia do Exílio (1922-1934), que reúne las novelas Os Condenados, $A$ Estrela do Absinto y A Escada Vermelha, el clima penumbrista produce voces y figuras enteramente nubladas, con un sabor anacrónico y a la vez de exiliadas, lo que confirma el título general de la serie. ${ }^{5}$

Ahora bien, ya en Macunaíma (1928), novela de Mário de Andrade llamada por su autor de "rapsódia", vamos a encontrar a un protagonista - "héroe sin ningún carácter", como lo señala el subtítulo, o "héroe de nuestra gente", como lo señala el narrador - que recorre, casi sin detenerse, practicamente todas las regiones del Brasil, desde la selva amazónica hasta São Paulo y Rio, con incursiones en el Nordeste y Centro-Oeste, personaje sincrético y ya una criatura del mestizaje étnico-cultural, sin moral ni psicología propias o profundizadas. En sus aventuras, entre picarescas, folclóricas, caricaturales o paródicas, esa desterritorialización, signo también del antiguo nomadismo indígena, es condición inata de su vitalidad y supervivencia en un estado de suspensión dramática y sobrevuelo de escenas y acciones en las cuales irrumpe, desencadena ciertos conflictos para muy velozmente escapárselos. Macunaíma siente mucha indolencia: "-Ai! que preguiça!..." es como un mote constante en la novela, crítica paródica del estereotipo colonial de la preguiça de los indios y también índice de un cierto tedio vital del protagonista, en quien los es- 
tados de alegría y tristeza se suceden y se intercambian imperceptiblemente como instantáneos juegos infantiles. Al Macunaíma es proporcionado el "derecho a la preguiça", pero no al reposo ni a las saudades: cuando las siente de verdad, solo en la selva - retorno a la aldea materna imposible - se muere. Su muerte es también un ritual de metamorfosis poético-cultural: Macunaíma se convierte en la constelación Ursa Mayor. Escuchemos ese desenlace:

A Ursa Maior é Macunaima. É mesmo o herói capenga que de tanto penar na terra sem saúde e com muita saúva, se aborrecen de tudo, foi-se embora e banza solitário no campo vasto do céu. ${ }^{7}$

Parece que esa resolución final de la narrativa no fue catártica. Pues de casi alma penada en la tierra de "pouca saúde e muita saúva", epíteto del Brasil por toda la "rapsodia", el Macunaíma-constelación sigue su vía errática, como nosotros la seguimos siguiendo, todos convertidos en condenados a aquel "banzo solitário" en esa vasta llanura del cielo. Banzo, palabra afro-brasileña que escuché por primera vez en un exilio nordestino, designaba la nostalgia muchas veces mortal que asomaba en el corazón de los esclavos negros desplazados violentamente de sus tierras, parientes, culturas y continente. Banzo solitário en la acción sinfín de banzar es uno de los peores destinos que uno pudiera encontrar. El entredicho de las saudades fue cambiado así por una pena más dura, ya que el otro nombre de banzoo solitário es el silencio estelar de la muerte - de Macunaíma y por supuesto de la "nuestra gente".

Aquí quizás cabría preguntarse: ?pero la condena a la vida errante, mito judaico-cristiano también pertinente a varias otras tradiciones milenarias, incluso en culturas nativas de las Américas, que revela al final sobre los espectros nacionales - en el sentido de aparición y de velación a la vez -, ya que sus sombras parecen ser poseedoras de un movimiento más universal o planetario, en la mejor matriz romántica, del hombre condenado a vagar indefiniblemente en una suerte de resonancia del mi- 
to faustiano? Yo diría que el aterrizaje forzado de nuestras figuraciones sin lugar tiende a domesticar lo indomable, a historicizar el no cronológico, a ubicar el punto extremo que ya no se deja y no se desea representar por medio del mapa. Aquí, la imposibilidad de su "nacionalización" es justamente lo que garantiza su existencia como espectros más bien que personajes. ${ }^{8}$ El primer grande historiógrafo brasileño de la corriente crítica moderna y que fue también un gran prosista, Capistrano de Abreu, ya en 1907, al publicar sus Capitulos de História Colonial (1500-1800), miraba, al final de ese ensayo clásico, con cierta revuelta melancólica, el paisaje del país pasados tres siglos de colonización. En el albor de los 1800, no había allí aún, según sus fuentes y ojos, ninguna señal concreta de sociabilidad, ni tampoco promesa futura. El ambiente seguía desolado y su juicio era contundente:

Vida social não existia, porque não havia sociedade; questões públicas tão pouco interessavam e mesmo não se conheciam: quando muito sabem se há paz. ou guerra, assegura Lindley. É mesmo duvidoso se sentiam, não uma consciência nacional, mas ao menos capitanial, embora usassem tratar-se de patrício ou paisano. $[\ldots]$

Cinco grupos etnográficos, ligados pela comunidade ativa da língua e passiva da religião, moldados pelas condições ambientes de cinco regiões diversas, tendo pelas riquezas naturais da terra um entusiasmo estrepitoso, sentindo pelo português aversão ou desprezo, não se prezando, porém, uns aos outros de modo particular -- eis em suma ao que se reduə̧iu a obra de três séculos. ${ }^{9}$

Esa visión algo melancólica de Capistrano poseeía muchas afinidades - en aquellos mismos años en que la escribía - con esos otros dibujos híbridos, a la vez impresionistas y expresionistas que Euclides da Cunha había justo terminado de exhibir sobre los lejanos sertones de Bahia, ${ }^{10}$ convirtiéndolos, con su estética más bien que pensamiento, de espacios antes olvidados y dramas perdidos, en escenas memorables. Pero aquí en ese itinerario yo prefiriré antes subrayárles las sus represen- 
taciones de los sertones de la selva amazónica. ${ }^{11}$ El territorio de Canudos hoy día puede quedarse habitado de historia y palabras, y así tan recalcado de muertos, gracias al incomún prosador poético de aquellas ruinas que ha sido Euclides. Con la Amazonia, en cambio, eso no se pasó, hay casi un proceso de olvido. Durante buena parte del año 1905, Da Cunha estuvo en el extremo noroeste de las fronteras brasileñas con el Perú, en una expedición diplomática y de reconocimiento de las cabeceras del río Purus, afluente del Amazonas (recuérdese que el escritor era, también ingeniero y eximio cartógrafo). Sus textos sobre ese viaje son magníficos. Intentaba, además, realizar por segunda vez su "venganza contra el desierto", como le gustaba decir (la primera por supuesto ya hubiera sido hecha en 1902 con el libro Los Sertones), y ahora haciendo eco al poeta Milton, le llamaría a ese proyecto ensayístico-literario sobre la Amazonia, que todavía no logró completar, "Un Paraíso Perdido". Entre las páginas de À Margem da História, obra que ha organizado pero que salió postumamente al final del mismo año de su muerte en 1909, se pueden encontrar todavía algunos de sus mejores escritos amazónicos. De entre ellos, "Judas-Asvero", quizás su mejor texto "vengador" de aquella serie, ya que allí alcanzala combinar magistralmente sus talentos de cronista, poeta y fabulista.

Así que en el sábado de Aleluya los seringueros o caucheros del Alto Purus "se desahogan de sus días tristes" y haciendo como en un "prodigio de estatuaria" construyen sus judas como espantajos de pañuelos y pajas e hierros viejos, fabricando esas "figuras disformes" con todo celo de escultores, rodeados por sus niños en algaravía. La venganza contra los sertones acuáticos y selváticos se convierte, en ese ritual, en venganza contra uno mismo. Si no, oigamos:

E o monstro, lento e lento num transfigurar-se insensivel, vai-se tornando em homem. Pelo menos a ilusão é empolgante...

Repentinamente o bronco estatuário tem um gesto mais comovedor do que o parla! ansiosissimo, de Miguel-Ângelo; arranca o seu próprio sombreiro; 
atira-o à cabeça de Judas; e os filhinhos todos recuam, num grito, vendo retratar-se na figura desengonçada e sinistra o vulto do seu próprio pai.

É um doloroso triunfo. O sertanejo esculpiu o maldito à sua imagem. Vinga-se de si mesmo: pune-se, afinal, da ambição maldita que o levou àquela ter$\mathrm{ra} ;[\ldots]^{12}$

Pero eso solo ya no le basta. Preparó en las vésperas una jangada que al margen del río "aguarda el viajero macabro". Cito:

O rio que lhe passa à porta é uma estrada para toda a Terra. Que a Terra toda contemple o seu infortúnio, o seu exaspero cruciante, a sua desvalia, o seu aniquilamento iníqu, exteriorizados, golpeantemente, e propagados por um estranho e mudo pregoeiro...13

E así el sertanejo de la selva y del agua echa la "jangada fantástica" con su "figura demoníaca", "hacia el hilo de la corriente". Y el desenlace de ese relato se fija en la narrativa de la peregrinación fluvial de ese judasfantasma-padre, doble del sertanejo abandonado, a la vez, por la naturaleza y por la civilización. Cito aún a Euclides:

E a figura desgraciosa, trágica, arrepiadoramente burlesca, com os seus gestos desmanchados, de demônio e truão, desafiando maldições e risadas, lá se vai na lúgubre viagem sem destino e sem fim, a descer, a descer sempre, desequilibradamente, aos rodopios, tonteando em todas as voltas, à mercê das correntezas, "de bubuia" sobre as grandes águas.

Não pára mais. À medida que avança, o espantalho errante vai espalhando em roda a desolação e o terror; as aves, retransidas de medo, acolhem-se, mudas, ao recesso das frondes; os pesados anfíbios mergulham, cautos, nas profunduras, espavoridos por aquela sombra que ao cair das tardes e ao subir das manbãs se desata estirando-se, lutuosamente, pela superficie do rio; os homens correm às armas e numa fúria recortada de espantos, fazendo o "pelo sinal" e aperrando os gatilhos, alvejam-no desapiedadamente. ${ }^{14}$ 
En el vértigo del río represéntase el drama de los senderos circulares en la selva de los cauchos como laberintos modernos y actualizados de la soledad, como alegorías de una historia interrumpida o ni siquiera empezada, como dibujos del ciclo infernal y arruinado de aquellas vidas fronterizas. Allí no hay más saudade, sino odio mortal. Pero el seringueiroescultor, el padre envuelto en las cismas del espíritu, en la mudez de sus muecas, el bruto vengador y autopunitivo, ya sin palabras, se queda en su caída al margen del agua, sin espejo ni esperanza, al borde de los talles de su transfiguración irónica que como él será pronto tragada entre el azar de los tiros y los remolinos furiosos de ese paisaje que es como una exacta "miniatura trágica del caos". Mientras tanto, su soledad no se extravía, sino en el simulacro que le sale como imagen de una traición a ser condenada a vagar por aquellas rutas hídricas sin paradero, hasta sus últimos destrozos.

En otra suerte de representación, en el bellísimo cuento "A Terceira Margem" de João Guimarães Rosa, es el propio padre que se va, partiendo sin mirar hacia atrás. No hay huellas. No se queda en ninguno de los dos márgenes conocidos del río, sino más bien en un tercer margen, utópico-imaginario de una parte, críptico-lunático de otra, espacio de deseos intraducibles y de silencios insondables, tiempo echado afuera de la historia y la memoria, sueño de cambio, pesadilla del no retorno, soledad sin abrigo ni geografía, poesía silente de gestos y afectos entre padre e hijo, el cual se presenta, en la voz del narrador, como el único hilo entre la vida en los márgenes de la corriente fluvial y el abandono del padre destinado a una frontera inalcanzable. Cito, en este verdaderamente admirable idioma poético inventado por Rosa:

Nosso pai não voltou. Ele não tinha ido a nenhuma parte. [...]

As vozes das notícias se dando pelas certas pessoas - passadores, moradores das beiras, até do afastado da outra banda - descrevendo que nosso pai nun- 
ca se surgia a tomar terra, em ponto nem canto, de dia nem de noite, da forma como cursava no rio, solto solitariamente. ${ }^{15}$

Es al hijo en este caso que le toca cargar los valijas de la memoria, de su culpa sinfín, de los víveres que deposita con celo todos los días al borde del río. Son "los bagajes de la vida", dice el narrador. No logra huir tampoco. No hay caminos de encuentro entre los tres márgenes. Así declara el narrador su obligación de permanencia:

Nosso pai carecia de mim, eu sei - na vagação, no rio, no ermo - sem dar razão de seu feito. $[\cdots]$ Sou homem de tristes palavras. De que era que eu tinha tanta, tanta culpa? Se o meu pai, sempre fazendo ausência: e o rio-rio-rio, o rio-pondo perpétuo. [...]

Ninguém é doido. Ou, então, todos. ${ }^{16}$

Y afinal, despues del trauma del encuentro con el fantasma de su padre, el hijo-narrador ya sin identidad reconoce:

Sou o que não foi, o que vai ficar calado.

Entre la amenaza suicida, la locura, el miedo y la renuncia, el deseo del hijo es de seguir al destino errático del padre, pero despues de su propia muerte:

Mas, então, ao menos, que, no artigo da morte, peguem em mim, e me depositem também numa canoinha de nada, nessa água que não pára, de longas beiras: $e$, eu, rio abaixo, rio a fora, rio a dentro - o rio. ${ }^{17}$

Ese río que se propaga y se repite a si mismo es un flujo del destierro, de la muerte y, más bien al contrario de una metáfora muy corriente, su fluir representa, antes que cualquier thélos, la suspensión de la historia. Los sobrevivientes son ahora los huérfanos sin padre, sin pedros 
ni páramos, y solo piedras y ningún paradero, son hecho y derecho: los sin patria. Ante la melancolía y la desilusión del progreso (el río no lleva a ninguna parte) no es posible tampoco erigir una sola patria a ser compartida, una nación a ser comulgada. Con Rosa, eso sí, volvemos al territorio de los mitos, el de una naturaleza vengativa y el del padre ausente.

El retorno a la casa no se efectua porque todavía ni siquiera hubiera alguna casa reconocible. Ese motivo es muy antiguo, milenar, y remonta, en la modernidad, por lo menos al romanticismo. En Brasil, con Joaquim de Sousa Andrade - que firmaba bajo el seudónimode Sousândrade -, en la segunda mitad del siglo XIX, ya el retorno a la casa paterna y a la vez al país de origen equivalían más bien a un llanto delante de un escenario en ruinas. ${ }^{18}$

O Guesa es un extenso poema épico-dramático compuesto parcelariamente en trece Cantos que tuvieran varias versiones y ediciones desde el año 1852 hasta 1902. Bajo la forma de libro hubo por lo menos nueve publicaciones del Guesa, tres de las cuales póstumas (y todavía solo de partes de algunos Cantos). Ya entre las seis ediciones hechas en vida, entre 1868 y 1888 (dos en São Luís do Maranhão, tres en Nueva York e una en Londres), sin duda la inglesa es la más completa, pero también falta. La crítica brasileña solo empezó efectivamente a reconocer el valor de Sousândrade en los años 1960, pero en general estuvo más interesada por los aspectos experimentales y vanguardistas de su obra, que posee alto poder inventivo y metalingüístico del lenguaje. Pero ese Guesa enteramente modernista pertenece a la vez a la mejor tradición romántica.

En un texto de Memorabilia que acompaña la edicción de Nueva York salida en 1876, Sousândrade afirmaba que su poema "nada tendría de dramático, ni tampoco de lírico o épico, pero simplemente de narrativo". ${ }^{19}$ Sin dejarnos llevar mucho por la retórica autoficcional del propio autor que, por el reverso del discurso de la sencillez de sus intentos y medios, más bien mezcla y refunde voces y géneros en un complejo juego de elaboración poética, queda claro ahí también, en la estructura misma del texto, un proyecto narrativo de largo espectro, con las alas imagi- 
narias de un panamericanismo bien marcado en su republicanismo reformista, a la vez visionario y crítico, sobre la historia de la modernidad en nuestros continentes.

Para empezar, el Guesa es un personaje directamente inspirado en la antigua mitología de los indios Muyscas, de Colombia, como indican dos muy extendidos y detallados epígrafes en la edición inglesa, sacados de relatos de Humboldt en Vue des Cordillères y del artículo "Colombie" escrito por el historiador francés C. Famin, especialista en numismática y amigo de Ferdinand Denis, en la enciclopedia L'Univers. Guesa quiere decir justamente el errante, sin casa, sem teto, homeless - por eso Sousândrade ha retirado la expresión errante del título de aquella misma edicíon, por considerarlo finalmente redundante en todas las ediciones anteriores: $O$ Guesa Errante. Así que Guesa, el joven viajero que fue sacado muy pequeño a fuerza de la casa paterna, en el pueblo andino de San Juan de los Llanos, debe seguir su ritual de soledad y preparación para ser sacrificado, al llegar de su edad juvenil, al Diós-Sol. Mientras tanto, hasta que el sacrificio se complete, el Guesa debe hacer la travesía del Suna, ruta sagrada y astrológica que le debe conducir hacia su destino. Así que Guesa también quiere decir algo como portador, porque su muerte sacrificial debería simbolizar magicamente el inicio de un nuevo ciclo de ciento y ochenta cinco lunas.

Ahora bien, la apertura del primer Canto ya es como una presentación de un amplio y naturalmente dramático panorama, el de las Cordilleras, dibujado con los colores de la estética de lo sublime:

Eia, imaginação divina!

$$
\text { Os Andes }
$$

Vulcânicos elevam cumes calvos,

Circundados de gelos, mudos, alvos,

Nuvens flutuando - que espetáculos grandes!

Lá, onde o ponto do condor negreja,

Cintilando no espaço como brilhos 
D'olhos, e cai a prumo sobre os filhos

Do lhama descuidado; onde lampeja

Da tempestade o raio; onde deserto

O azul sertão formoso e deslumbrante

Arde do sol o incêndio, delirante

Coração vivo em céu profundo aberto? ${ }^{20}$

La peregrinación del Guesa mantiene el sentimiento melancólico de la proximidad de su pena capital, así como de la imposibilidad de retorno o reconciliación con el país natal, ya que Sousândrade, en su internacionalismo modernista, extiende y amplifica el trayecto de su héroe a través de los Cantos para más allá de las fronteras nacionales y americanas, construyendo un viaje cosmopolita con larga dimensión espacial y temporal. En el famoso Canto Décimo, hay toda una parte vertiginosa, con elevada dosis de transgresión poética y crítica social, que fue llamada por la crítica "El Inferno de Wall Street", verdadera polifonía de lenguas, personajes, deseos, hechos dramáticos y efímeros en un ritmo casi delirante y propio al de los rotativos de los grandes diarios y revistas. Compuesto a partir de 1873, es una de las miradas más irónicas, visionarias e inventivas sobre el ascenso del capitalismo yanqui en las literaturas del siglo XIX. La llegada del Guesa a las "murallas" de la Big Apple y su entrada en el "Inferno" son antológicas:

\section{[‥] No Hudson. Pára o Guesa perslustrando.}

Bebe à taberna às sombras da muralha

Mal sólida, talvez, de Jericó

Defesa contra o Índio - E s'escangalha

De W all-Street ao ruir toda New-York:

(O Guesa tendo atravessado as ANTILHAS, crê-se livre dos XEQUES e penetra em NEW-YORK-STOCK-EXCHANGE; a VOZ, dos desertos:) 
- Orfeu, Dante, Eneas, ao inferno

Desceram; o Inca bá de subir...

= Ogni sp'ranza laciate

\section{Che entrate..}

- Swendenborg, há mundo porvir?

(Xeques surgindo risonhos e disfarçados em Railroad-managers, Stockjobbers, Pimpbrokers, etc., etc., apregoando:)

\footnotetext{
- Harlem! Erie! Central! Pennsylvania!

= Milhão! cem milhões!! mil milhões!!!

- Young é Grant! Jackson,

Atkinson!
}

Vanderbilts, Jay Goulds, anões!

$[\cdots]$

(NORRIS, Attorney; CODEZO, inventor, YOUNG, Esq., manager; ATKINSON, agent, ARMSTRONG, agent, RHODES, agent, $\mathrm{P}$. OFFMAN \& VOLDO, agents; algazarra, miragem; ao meio, O GUESA:)

- Dois! três! cinco mil!! se jogardes,

Senhor, tereis cinco milhões!

= Ganhou! ha! haa! haaa!

- Hurrah! ab!...

- Sumiram... seriam ladrões?.... ${ }^{21}$

Pero la vibración alucinante de cuerpos, negocios e ilusiones significa en el conjunto del poema algo como cerca de apenas 9\% del total. Incluso si ahí sumáramos una otra parte "experimental" del Canto Segundo, conocida por "Tatuturema", en la cual se narra de forma nerviosa y vibrante una grande fiesta sabática indígena, la proporción entre pasajes 
que nitidamente juegan en los límites del lenguaje y el poema en su unidad mayor no pasaría del 14\%. El tonus dominante sigue siendo el del épico-dramático en el mejor linaje romántico del tránsito melancólico y trágico entre saudades y soledades.

Si la casa de nascimiento y niñez en el Maranhão yace en ruinas (tema de todo el Canto Quinto), esas visiones provienen también, en gran medida, de la historia colonial y social contemporánea a la propia memoria autobiográfica del Guesa/Sousândrade. Así que me gustaría terminar esa lectura referiéndome rapidamente a uno entre tantos pasajes que podrían traer nuevas luces sobre la visión histórica y literaria del autor, alrededor de esa forma en que se manifiesta la imposibilidad de una narrativa nacional unitaria y libertaria a la vez. En el Canto Segundo, aún con los indios, la melancolía invade la escena a partir de la percepción que la memoria de los nativos ya hubiera sido eclipsada por el proceso de su extinción. Cito:

\footnotetext{
Ob! como as noites de Manaus são tristes

As cismas na soidão dos infelizes!

Quando tu, esperança, não existes

Com teu belo horizonte de matizes,

Saudade minha... - Estão, densa a ribeira

Fogueiras longe os Índios acendendo;

$[\cdots]$

Ante os destinos seus, da tribo extinta

Do egoísmo ao contacto, co'o gemido

Que geme o Indio inocente, e a dor lhe pinta.22
}

En una canción-manifiesto del movimiento musical Bossa Nova, el compositor y cantante João Gilberto desafinaba su voz y desafiaba al público, con el verso-protesta: 
- Chega de saudades!...

Antes de que ustedes me lancen a mí el mismo grito, yo concluyo para no tener quizás que huir como lo hicieran el Guesa, el Judas-Asvero, el padre del tercer margen, el Macunaíma, João Miramar y Serafim Ponte Grande, el Brás Cubas, los locos demónios de Lima Barreto, los indios y mestizos nómades de Capistrano, las ancianas paralíticas en el asilo de la memoria de José Geraldo Vieira. Las soledades son las más anchas, profundas o estrechas en el mundo, son las soledades de cada uno; y las saudades, si nuestro "saudosismo" no las quiere traducibles, entonces yo prefiero la palabra de orden de João Gilberto y basta. Pero sí, si ustedes la desean y todavía pueden traducirla, aquí y ahora, para todos los idiomas y lenguas que conozcan o inventen, no importa, yo prefiero más bien ese otro método con toda su política. O sea, con esa otra política que sigue propugnando, contra la globalización del presente, el nuestro deseo y derecho a la libre traducción, que se podría todavía traducir como: decir no al monolinguismo de la razón imperial ${ }^{23}$ - y muy específicamente diciendo no a sus máquinas de traducciones unívocas - y proseguir con la babel de lenguas francas, dialectos, idiolectos, multitudes de gestos y palabras. Con alegrías tristes o tristezas alegres, pero con esperanza de que, más allá de las soledades antiguas, modernas y postmodernas podríamos, si así lo deseáramos, sentir y compartir saudades del futuro en ese claro instante. Nadie ni nada lo impiden.

\footnotetext{
Notas

* Este texto serviu de base para conferências que realizei nas universidades de Berkeley, Colorado (Boulder), Stanford e Tulane (New Orleans), quando de minha estadia na Califórnia, na primavera de 2000, bem como para a exposição que fiz no VII Congresso Internacional da Abralic, em Salvador, em julho do mesmo ano. Mantive aqui sua estrutura original, mais conforme ao caráter oral das intervenções acima assinaladas.
} 
1 Este artículo fue escrito en una estadía en el Department of Spanish and Portuguese, en la Universidad de California, Berkeley, durante la primavera de 2000. Debo agradecer al profesor Dru Dougherty por la invitación a una public lecture que posibilitó la escritura de su primera versión. Julio Ramos hizo una atenta y valiosa lectura que contribuyó bastante hacia su forma final. Clelia Donovan ha revisado el sumario en ingles que acompañó su ponencia. Los errores eventuales son de mí entera responsabilidad.

2 J.G. Vieira, "Depoimento". In: F. Goes (ed.). José Geraldo Vieira no Quadragésimo Ano de sua Ficção. São Paulo, 1979, p. 102.

3 El imagen presente en la narrativas de los viajeros en Brasil y también en La Vuelta al Día en Ochenta Mundos de J. Cortázar fue subrayada por Flora Sussekind en su ensayo $O$ Brasil Não Fica Longe Daqui, São Paulo, 1990.

4 Sobre el autor, ver la biografía de Francisco de Assis Barbosa, A Vida de Lima Barreto, Rio de Janeiro, 1952; el estudo crítico original de Antonio Arnoni Prado, O Crítico e a Crise, Rio de Janeiro, 1976 (reedición ampliada, São Paulo, 1991); y las contribucciones más recientes de Roberto Vecchi, L’Estetica della Ribellione, Bologna, 1992, e Beatriz Resende, Lima Barreto e o Rio de Janeiro em Fragmentos, Rio de Janeiro/Campinas, 1993. Ver también el ensayo de Roberto Vecchi: "Seja moderno, seja brutal: a loucura como profecia da história em Lima Barreto". In F. Foot Hardman (ed.). Morte e Progresso: cultura brasileira como apagamento de rastros. São Paulo, 1998.

5 Para un balance crítico menos eufórico véase Alfredo Bosi, História Concisa da Literatura Brasileira, São Paulo, 1970, pp. 400-05. Sobre la poesía de Oswald y sus impases ideológicos, yo hizo un artículo aún inédito: "Algumas fantasias de Brasil: o modernismo paulista e a nova naturalidade da nação".

6 Ver el admirabel panfleto revolucionario de Paul Lafargue, Le Droit à la Paresse, Paris, 1880 (trad. bras., São Paulo, 1980). Entre la numerosa crítica de Macunaima, véase la reciente contribucción de José Luiz Passos en Ruinas de Linhas Puras: quatro ensaios em torno a Macunaima, São Paulo, 1998. En "Lacrimosa" el autor discute muy bien la cuestión del desplazamiento básico del héroe de "nuestra gente". Ya en el epílogo, "Por uma tanatologia do Macunaíma", analiza com pertinacia la cuestión de su muerte.

7 M. de Andrade, Macunaima, Belo Horizonte/Rio de Janeiro, 1997, p. 124. 
8 La inspiración teórica para ese desarrollo está en el interesante aporte de Benedict Anderson en The Spectre of Comparisons: nationalism, Southeast Asia, and the world. London/New York, 1998.

9 J. Capistrano de Abreu, Capitulos de História Colonial (1500-1800). 4a. ed., Rio de Janeiro, 1954, pp. 337-38. Ver, también, en la buena traducción en inglés:

There was no such thing as social life - there was no society. At best, according Lindley, people knew whether or not they were at war. Even though they called one another by patriotic names such as patricio or paisano, it is even dubious whether or not they felt they were citizens of a captaincy, much less of a state. [...]

"Our five etnographic groups were actively linked by a common language and passively linked by their religion. They were shaped by the environmental circumstances of five different regions. They were intensely enthusiastic about the country's natural resources. They were adverse to or scornful of the Portuguese, but did not think especially bighly of one another either. After three centuries, this is how we were." (New York/Oxford, 1997, p. 202).

10 Esa lectura está presente en Franklin de Oliveira, inspirado por su vez en famosa análisis de Gilberto Freyre. Ver "Euclides da Cunha”. In A. Coutinho y E. F. Coutinho (eds.). A Literatura no Brasil. Rio de Janeiro, 1986, v. 4, cap. 38.

11 La posible origen del término sertão a partir del idioma nativo angolano bunda, que designaba la selva más distante y inhóspita como michitu, muchitu ou muchitum - y de ahí derivándose las palabras lusas muceltão, celtão y certão - fue sugerida por Gustavo Barroso en el artículo "Vida e história da palavra sertão". Salvador, 1983 (1a. ed.: Rio de Janeiro, 1952). Agradezco al filólogo estudioso de Euclides da Cunha y mí amigo Frederick Amory, de Berkeley, por esa importante referencia.

12 E. da Cunha, Obra Completa, Rio de Janeiro, 1966, v. I, pp. 265-66. Cita cotejada con la edición original: Á Marjem da Historia, Porto, 1909, p. 107. Y también con la primera edición en Brasil: À Margem da Histéria, São Paulo, 1967, p. 76.

13 Idem, 1966, p. 266. Ver ibidem, 1967, p. 76.

14 Id., 1966, p. 266. Ibidem, 1967, p. 77.

15 J. Guimarães Rosa, “A terceira margem do rio". In Primeiras Estórias. Rio de Janeiro, 1985, p. 33. La primera edición en libro es del año 1962.

16 Idem, ibidem, pp. 35-6. 
17 Id., ibid., p. 37.

18 Ese tópico fue bien subrayado por Flora Sussekind, en especial a partir del análisis del Canto Quinto de O Guesa, en "Brito Broca e o tema da volta à casa no romantismo". In Remate de Males. Campinas, IEL/UNICAMP, (11), 1991. Reproducido también en el libro de su autoría, Papéis Colados, Rio de Janeiro, 1993.

19 Frederick G. Williams y Jomar Moraes (eds.). Sousândrade: Prosa. São Luís, 1978, p. 14. Sobre el autor, utilizo también otros trabajos importantes desde el punto de vista historiográfico y crítico. Véanse: Frederick G. Williams, Sousândrade: Vida e Obra. São Luís, 1976; Williams y Moraes (eds.), Sousândrade: Inéditos. São Luís, 1970; Francisco Marialva Mont'Alverne Frota, Sousândrade: o último périplo. São Luís, 1977; Haroldo de Campos y Augusto de Campos, Revisão de Sousândrade. Rio de Janeiro, 1982 (que contiene también estudio inaugural de Luiz Costa Lima).

20 J. de Sousandrade, O Guesa. London: Cooke \& Halsted, The Moorfields Press, /1888/, p. 3. Véase la utilización, en ese pasaje, de la palabra sertão para representar el paisaje vacío, amplio y panorámico del cielo, del horizonte azul y ancho desde una gran altitud. Lo que parece confirmar los comentarios hechos arriba en la nota 11. Yo diría, quizá incluso hacia más allá: sertão podría utilizarse como sinónimo más general del "infinito natural" que estaba asociado al imagen del sublime en las representaciones románticas del paisaje.

21 Idem, ibidem, pp. 230-33.

22 Id., ibid., p. 43.

23 Esas palabras finales están directamente inspiradas por la lectura que estoy haciendo en este momento del instigante libro-manifiesto de Michael Hardt y Antonio Negri, Empire, Cambridge (Mass.), 2000. Véase también el magistral ensayo "Crítica de la Pirámide" de Octavio Paz, en Postdata, México, 1970, despues reeditado juntamente con El Laberinto de la Soledad. También apóyome aquí en Jacques Derrida, Le Monolinguisme de l'Autre, ou, La Prothèse d'Origine. Paris, 1996 (trad. ing.: Stanford, 1998). 